\title{
VISITANTES DO BRASIL NO SÉCULO XVII.
}

A literatura de viagens é fundamental para a reconstrucão histórica. Ela fornece ao historiador a imagem que os estrangeiros fazem de nós, sempre tão diferente da idéia que nós mesmos fazemos da nossa terra e da nossa gente e da própria História que produzimos e que os historiadores procuram recriar. A bibliografia exótica brasileira constitui, assim, documentação capital que deve sempre ser examinada. E'stas notas não incluem os viajantes franceses e holandeses que aqui estiveram como conquistadores, nas lutas pela posse do Maranhão e do Nordeste, mas tão sòmente os que estiveram de passagem e escreveram impressões de viagem. $\mathrm{E}$ is. to sem esquecer que desde 18 de março de 1604 se proibira a vinda de estrangeiros para o Brasil e desde 12 de dezembro de 1605 se ordenara o internamento, a 12 léguas da costa, dos estrangeiros nela encontrados. Assim, de 1604 a 1800 (1) são raríssimos os viajantes estrangeiros que aqui chegam, acidentalmente, pedindo acolhida momentânea para refrêsco e abastecimento, ou providos de uma licença especial d'El Rey para aqui se abrigarem, mesmo provisòriamente.

A partir do século XIX, "o verdadeiro século do descobrimento de nosso país para as nações civilizadas", a história dos viajantes e de suas obras transforma-se na história das €xplorações científicas, como mostrou Rodolfo Garcia no magistral estudo que sob êsse título publicou (2), e constitui canítulo independente da historiografia.

François Pyrard, nascido em Laval, desejoso de ver e aprender, embarcou a 18 de maio de 1601 no navio Corbin, que juntamente com Le Croissant formava a frota equipada por

(1). - A data de 1800 refere-se à Carta Régia determinando ao governador e capitão-general do Pará, d. Francisco Maurício de Souza Coutinho verifique se "um tal barão de Humboldt, natural de Berlim", tem viajado ou viaja pelos territórios da capitania do Maranhão, "pois seria sumamente prejudicial aos interêsses políticos da Corôa Portuguêsa, se se verificassem semelhantes fatos".

(2). - "História das Exploraçóes Científicas", Diccionatio Historico, Geographico e Ethonografico do Brasil, Inst. Hist. e Geog. Bras., Rio, 1922, 856-910. 
uma Companhia Mercantil organizada em 1601 por mercadores de Saint Malô, Laval e Vitré, para procurar os caminhos da Índia e mostrar aos franceses como chegar ràpidamente às fontes comerciais. Durante 10 anos circulou pelo mundo entre diversas espécies de povos, conhecendo seus costumes e maneiras de agir. Nenhum francês o fizera antes. Saindo de Saint Malô seguiram os navios em direção ao Cabo, onde se encontraram com Spilbergen, e ancoraram na ilha de São Lourenço (Madagascar), onde permaneceram 3 meses. A 2 de julho o Corbin naufragou nas costas das ilhas Maldivas e François Pyrard, aprisionado com alguns companheiros, aí ficou retido 5 anos. Conseguindo libertar-se, seguiu para o $\mathrm{Ca}-$ lecute, onde passou 8 meses, até obter licença para dirigir-se a Gôa, único lugar onde encontraria transporte para sua volta à França. Partiu na esquadra portuguêsa, dominadora dos mares Índico e Arábico, e em Gôa permaneceu um ano e meio, primeiro doente, depois prêso e, finalmente, como soldado em diversas campanhas pela costa de Gôa, Ceilão, Malaca, Sumatra e Molucas. Chegara em junho de 1608 e iniciava a viagem de volta a 3 de janeiro de 1610 . As dificuldades da navegação trouxeram-no à Bahia, onde aportou a 13 de agôsto de 1610 e permaneceu até 7 de outubro, chegando a Rochelle a 16 de fevereiro de 1611.

Seu Discours du Voyage des François aux Indes Orientales (Paris, 1611) (3) é provàvelmente o primeiro depoimento francês, muito vivo e curioso, sôbre as proezas da navegação ultramarina. Suas aventuras pelos mares orientais lêemse como um romance. Há duas descrições excelentes: a das ilhas Maldivas, onde viveu 5 anos, e a de Gôa, cujo poder, como sede do vice-reinado português, então dominador, e cuja riqueza surpreenderam o autor tão pouco simpático aos portuguêses. Por isso mesmo a narração adquiriu um ar de sinceridade que invade e acredita o livro. A descrição do Brasil, cuja costa avista de longe como uma sucessão de alvos lençóis de linho, particularmente a da Bahia, onde passa 2 meses, ó rápida, apressada, e contém eqüívocos. O Brasil era "um pays assez rude et sauvage" e suas florestas perto das cidades estavam repletas de macacos. Não tinha relações comerciais, não

(3). - 1a. edição. Existem outras ediçôes: Paris, 1615, 2 vols.; Paris, 1679, 3 vols., (sôbre essa vide José Carlos Rodriǵues, Biblioteca Brasiliense, n. 2007); Londres, Hakluyt Society, 1887, 2 vols.; trad. parte de J. H. da Cunha Rivara, Nova Gôa, 1858-1862, 2 vols.; ed. rev. e atualizada: de $A$. de Miagalhães Bastos, da versão de J. H. da Cunha Rivara, Liv. Editôra Civilização, Pôrto, 1944, 2 vols. 
se bastava de modo a poder nutrir os portuguêses e se não fôsse a grande quantidade de açúcar e de prata que vinha do Rio da Prata, não haveria do que nele viver; tudo era excessivamente caro. Tudo estava no litoral, pois não ousavam os portuguêses penetrar o interior, e a pesca da baleia era outra fonte de renda. Descreve os índios, seus costumes e hábitos. Serve seu Discours como elemento de contraste com os cronistas da época, e os viajantes como Dampier, que visitaram a Bahia em 1699.

Richard Flecknoe (1600-1678), poeta medíocre e péssimo escritor de viagens, nasceu em Londres. Religioso, não jesuíta, como se pensou, chegou ac Rio de Janeiro na frota de Salvador Corrêa de Sá e Benevides, aos 16 de janeiro de 1648 . Ficou um semestre no Rio, voltando à Europa em agôsto daquele ano, na frota de D. Rodrigo de Alecanstro (4). Aqui conviveu com Simão de Vasconcelos, mas sua relação é muito pobre. as notícias sôbre os índios insignificantes e a descrição do Rio de uma miopia desoladora, resumida e falha de interêsse. Mas apesar de tudo, como disse Boxer, Flecknoe foi um dos primeiros, talvez o primeiro viajante estrangeiro, a descrever o Rio como "the pleasantest place in the world for natural landscape". A Relation of Ten Years Travells in Europe, Asia, Affrique, and America. All by way of Letters occasionally written to divers noble Personages from place to place constitui uma das mais raras peças da brasiliana exótica rara (5) .

Desde 1934 estava publicado o Jornal ou Diário de bordo de Edward Barlow, um simples marinheiro de profissão que,

(4). - Vide Afonso de E. Taunay, "Ricardo Flecknoe" (sic) in Visitantes do Brasil Colonial, Brasiliana, vol. 19, 2a. ed. 1938, 35-83. Taunay descreve o livro, composto de 32 cartas, e traduz as referências ao Brasil (65-83), do exemplar raríssimo da Biblioteca do Itamaratí, que pertenceu ao Barão do Rio Branco. Alfredo de Carvalho também possuiu um exemplar e o descreve em sua Biblioteca Exótica Brasileiran Rio de Janeiro, 1930, II, 161-162. Charles Boxer fêz uma descrição de viagem baseada na Relation, (cf. Híspanic American Historical Review, vol. XXVIII, 1948, 501-502) e em conferência pronunciada no Rio de Janeiro corrigiu alguns enganos correntes da biografia de Flecknoe. Vide "Three Englishmen in colonial Brazil, 1588-1644", in Bulletin of the Sociedade Brasileira de Cultura Inglêsa (Rio de Janeiro), novembro de 1949, vol. IV, n. ${ }^{\circ}$ 3, pp. 13-16, do qual um extrato foi publicado no Correio da Manhã (Rio, 2 de outubro de 1949) sob o título "Três inglêses no Rio de Janeiro de (sic) seiscentos". Numerosas referências a Flecknoe se encontram também na obra do mesmo autor Salvador de Sá and the Struggle for Brazil and Angoliz, 16021608, Londres, 1952 .

(5). - A melhor descrição bibliográfica com! todos os títulos dos capítulos in Biblioteca Americsna, parte V, Catalogue n.o 479, Maggs Bros, Londres, 1926, n. ${ }^{a} 4308$, p. 28 . A obra de Flecknoe foi impressa em Londres em 1654. As outras obras do Autor, poesia, teatro e epigrama in The British Museum Catalogue of Printed Boaks, 1881-1900, vol. 18, 1946, pp. 190-191. 
em 1663-1664, esteve no Rio de Janeiro; coube porém a Charles Boxer revelá-lo aos estudiosos brasileiros, que o descorheciam. Numa conferência pronunciada em 1949, Boxer resumiu a documentação portuguêsa sôbre a licença para a viagem e contou a ajuda que Barlow e outros marinheiros ingiêses prestaram na construção de um grande galeão que êle identificou com o Padre Eterno, nos estaleiros da ilha do Governador (6). Sabia-se da proibição de viagens de navios estrangeiros ao Brasil (7) e da construção do Galeão (8) mas desconhecia-se a viagem de Barlow, que fornece curiosas informações sôbre costumes do Rio de Janeiro da segunda metàde do século XVII e o auxílio inglês àquela construção.

Barlow deixou Lisboa antes da concessão da licença e Funchal em maio de 1663, em direção ao Rio. A viagem foi péssima, ao contrário da de Flecknoe (9), e demorou onze semanas na travessia de Funchal ao Rio. Barlow aqui permaneceu 5 meses, tendo desenhado com grande habilidade artística o pôrto cio Rio quando do lançamento do Galeão (10) e partiu entre 13 a 28 de janeiro de 1664 para Lisboa. Afora curiosas informacōes sôbre a flora e fauna do Brasil, Barlow observou que o país era muito abundante de açúcar, e era aqui que melhor o produziam; o Rio, Bahia e Recife todos os anos carregavam muitos navios com açúcares, tabaco e pau brasil para os mercadores de Portugal, o que significava um grande enriquecimento para esta Corôa, sem o qual ela seria um pobre Reinado (11).

Desde a infância Gabriel Dellon se apaixonara pelas viagens; formado em medicina, partiu para Paris, decidido a deixar a França e a satisfazer sua curiosidade de conhecer os costumes estrangeiros. Saiu do Havre a 20 de março de 1668 ,

\footnotetext{
(6). - "Três inglêses no Río de Janeiro de (sic) seiscentos" in Correio da Manhä (Rio, 2 de outubro de 1949).

(7). - Legislação publicada in J. J. Andrade e Silva, Co'eção Cronológica de Legist. ção poztuǵuêsa, Lisboa, 1854, e Documentos Históricas, Biblioteca Nacional do Rio do Janeiro, vol. XXI, pp. 351-353 e LXVI, p. 188.

(8). - Terra Goytacá à Luz de Documentos Inóditos, Paris, 1913, I, 77-78 e Documentos Históticos da Biblioteca Nacional do Rio de Janeiro, vol. III.

(9). - Boxer compara a descrição de Flecknoe e Barlow in "English Shipping", artigo cit., pp. 224-225.

(10). - O Jơnal ou Diário de bordo guarda-se no Museu Marítimo de Greenwich, fundado em 1934 para ilustrar a história marítima da Grã-Bretanha. Foi publicado por B. Lubbock, Bariow's Journal of his Life at Sea in King's Ship, East and West Indiamen and other merchantmen from 1659 to 1703 , London, 1934 . Um pequeno resumo in Charles Boxer, "English Shipping in the Brazil Trade, 1640-1655", The Mariner's Mirror, vol. 37, n. ${ }^{\circ} 3$, julho de 1951, 223-227. Referencias in Charles Boxer, Salvador de Sá and the Struggle for Brazil and Angola, 1602-1686. London, 1952, 330-331.

(11). - Charles Boxer, "English Shipping", art. cit., 228.
} 
no navio La Force, da Companhia Real, em direção ao Oriente, e a 29 de setembro chegava a Madagascar. Viajou depois para Surate, Malabar, Calecute, Gôa, Cameron, Ormiz, Damão. Acusado como herético ao Santo Ofício, por haver sustentado opiniões sôbre o abuso e intimidades das imagens santas pelos portuguêses, tendo sido seus denunciadores poderosos rivais em aventuras amorosas (12) foi aprisionado a 24 de agôsto de 1673 . Condenado a 5 anos de prisão, depois de viver 2 anos e meio nos cárceres de Damão foi embarcado a 27 de janeiro de 1676 em Gôa para apresentar-se à Inquiisição de Lisboa. Na viagem de volta chegou à Bahia de Todos os Santos a 19 de maio, onde permaneceu até 3 de setembro quando partiu para Lisboa, alcançada a 15 de dezembro. Depois de muitos esforços e da intervenção de amigos, especialmente de Bossuet, a quem chama seu libertador, conseguiu livrar-se da Inquisição, chegando à França (Bayonne) a 16 de agôsto de 1677. Fôra tal o rigor do tratamento que chegara a pensar em suicidar-se (13). Dellon continuou a exercer sua profissão e em 1685 acompanhava à Hungria os príncipes Conti, como médico; ainda vivia em 1709, quando publicou a nova edição de suas viagens, dedicada ao Barão de Breteuil.

Em 1685 publicou sua Relation D'Un Voyage des Indes Orientales (14), que vinha escrevendo desde sua volta para satisfazer a curiosidade de amigos. $O$ acidente imprevisto que $u$ obrigou a partir precipitadamente para a Europa o impediu de incluir muitas observações que vinha anotando. $\mathrm{Na}$ Relation d'un Voyage, pelo receio de quebrar o juramento de segrêdo, não diz nada sôbre sua condenação pelo Santo Ofício, nem que co chegar ao Brasil, lhe tiraram os ferros e lhe permitiram sair de dia, enquanto esteve na Bahia, só o fazendo na Relation de l'Inquisition (15) publicada três anos depois. Numa como noutra. Dellon parece sincero e verdadeiro e descreve os mesmos lugares com pequenas variações. Gôa, que conheceu bem, aparece como uma das mais florescentes cidades orientais, mas são

\footnotetext{
(12). - Relation de 'Inquisition Paris, 1688, 10-13 e 52 .

(13). - Ob. cit., 53-58

(14). - 1a. ed. Paris, Claude Barbon, 2 vols; 2a. ed. Atriterdam, 1699; trad. ingl., Londres, 1688; trad. alemã, Dresde, 1700; 3a. ed. Voyaǵe $M$. Dellon avec sa Relation de i'Inquisition de Goa.. Amsterdam, 2 vols.; 4a. ed., Colônia, 1709-1711, 3 vols. O Traité de Maladies Particuliers aux Pays Orintaux et Dans la Rorte, Paris, 1685 é muito curioso para história da medicina. Descreve com detathes o Bicho que tanto atacou os brasileiros $(51-56)$ e o que os portuguêses chamavam "csfalfados" devidos especialmente aos excessos sexuais (42-45).

(15). - Ob. cit., 199. No entanto declara na Relation d'un Voyage que o capitão do navio the pedira que servisse a bordo como médico, o que faz supor que não andasse de ferros, 120 .
} 
as duas descrições da Bahia, com as variantes, que nos interessam. Dellon considera a Bahia muito agradável, o ar bom e temperado pelas chuvas freqüentes. Enumera as frutas, diz que o açúcar é a principal riqueza do Brasil, descreve as drogas e alimentos, a pesca da baleia, trata dos habitantes e seus costumes, dos escravos, e dedica um capítulo à cidade e pôrto da Bahia, "a maior de tôdas aquelas que os portuguêses possuiam no Brasil", e onde "o vício reina soberanamente".

No prefácio da Relation d'une Voyage declara que não escreveu sôbre o Brasil baseado em relações de outros, mas no capítulo XXIV, sôbre sua chegada, diz que diversas pessoas já escreveram sôbre o país, o que pode revelar seu conhecimento da literatura de viagem ao Brasil dos séculos XVI e XVII. Na Relation de l'Inquisition, escrita três anos depois, a descrição é mais completa em certas particularidades da cidade e dos habitantes.

"Le Brésil à cela de particulier, qu'il n'y a personne qui soit reduit a ce point de misére, que mandier son pain, \& les malhereux qui y viennent des pays éloignez quelques incapables qu'ils puissent être de travailler, ne sont jamais rejettez par les personnes qui ont du bien, chacun se faisant un point d'honneur de retirer chez soy autant des miserables qu'il y en peut venir..." (16).

Escreve que as cidades alta e baixa reunidas são, pelo menos tão grandes quanto Lyon e talvez mais povoadas; na alta há belas ruas, casas soberbas, igrejas magníficas, e o palácio do Governador, onde também se aloja a Relação, é de uma grandeza e de uma beleza pouco comuns. Descreve melhor os costumes sociais e a riqueza do comércio urbano e marítimo (17) . A Relation de l'Inquisition distingue-se também pela relação das crueldades e infâmias daquele Tribunal, considerado, pelo Autor, mais rigoroso que os da Itália e Espanha, e pelas belas gravuras sôbre os autos, a sala e os condenados.

Francisco Coreal (1648-1708), nascido em Cartagena, partiu em 1666 para a América, percorrendo, durante 17 anos as Antilhas, a Flórida, o México, a América Central e a Nova Granada. No princípio de 1684, voltou à Espanha, a fim de receber uma herança paterna e logo seguiu para Lisboa, onde embarcou na frota do Brasil, chegando à Bahia a 31. de outubro de

(16). - Relation de l'Inquisition, 204.

(17). - Ob. cit., 205-208. 
1685 (18). Coreal permaneceu 5 anos no Brasil, conhecendo especialmente a Bahia, São Paulo e o Rio de Janeiro, donde partiu para Buenos Aires, Perú, Panamá, Havana e daí para Cádiz. Escreveu a relação de suas viagens pouco antes de morrer, $€ \mathrm{~m} 1708$ (19). Descreve a cidade do Salvador e os costumes relaxados de sua gente, dominada pela paixão sexual, pela ociosidade e pela fanatismo religioso. Narra as aperturas da vida dos escravos negros, muito mal tratados pelos senhores, e pre$v \hat{v}$ as revoltas negras que mais tarde perturbaram a Bahia. Visita, depois, a capitania de São Vicente, descreve o pôrto de Santos como um dos melhores do mundo, trata da gente indígena e mestiça de índios que constituiam sua maior parte, fala das minas de prata e dos tributos, o quinto do ouro que deviam pagar e da independência do povo, que tornava São Paulo uma pequena república; descreve as bandeiras paulistas, que faziam incursão de quatrocentas a quinhentas léguas pelo interior do país, indo até aos rios da Prata e ao Amazonas, atravessando tocio o Brasil. Enumera as várias tribos e seus costumes e conta uma aventura amorosa com uma senhora casada, que em tudo, diz Alfredo de Carvalho, se assemelha à que Pyrard de Laval referiu como the tendo acontecido na Bahia em 1610 .

E' pela inexistência do original espanhol, e por não admitir a hipótese pouco plausível de tradução feita do manuscrito (20) que Alfredo de Carvalho levanta a hipótese de serem espúrias as Viagens ou de pertencer "ao número das compilações apócrifas e contrafações clandestinas com que os prelos holancleses inundaram a Europa no século XVII". Mantém-se, aliás, em atitude reservada, declarando que se tratava de um problema bibliográfico, e que "apócrifa ou genuína, a obra encerra notícias curiosas, entre outras, das visitas feitas pelo suposto viajante, ou outros contemporâneos, a várias partes do Brasil de 1685 a 1699 . Desta suspeita, cuja discussão foi deixada em suspenso, Rubens Borba de Moraes partiu para a afirmação de

(18). - Alfredo de Carvalho fêz o melhor estudo sôbre êste viajante; cf. "Um GưlobeTrottex" do século XVII", RIHGB, t. LXXII, 7-20, reproduzido in Aventuras e Aventureiros no Brasil, Rio, 1929, 205-216.

(19). - B. Sánchez Alonso, História de I/x Historiografía Española, Madrí, 1950, III, 54. A obra se intitula, Voyagel de François Coreal aux Indes Occidentales, Amsterdam, J. F. Bernard, 1722, 3 vols.; 2a. ed. Paris, 1728; 3a. ed. Amsterdam, 1736 e 4a. ed. Paris, 1778 .

(20). - Alfredo de Carvalho declara que não se conhese edição espanhola e cita 0 inventário de Serrano y Sanz, Autobiografias y Memotias. Sánchez Alonso também desconhece original manuscrito e edição espanhola cf. Fuentes de la Historia Española e Hispızno Americana, Madri, 1927; I, n.o 7774. 
que Alfredo de Carvalho demonstrou a não existência do autor e que o livro foi "fabricado", baseando-se em relações de viagens verdadeiras, sobretudo Froger e Pyrard de Laval. "Repete, com mais literatura, o que disseram êsses autores" (21). Não nos parece que Alfredo de Carvalho tenha demonstrado a apocrifia, mas tão sòmente suspeitado da genuidade da viagem. A possibilidade de ser feita a tradução diretamente do original e não de edição não pode ser posta inteiramente de lado, especialmente quando se diz, como faz Sánchez Alonso, que o autor antes de voltar à pátria esteve na Holanda (22). As observações sôbre a independência dos paulistas, que formaram uma pequena república, sôbre a dissolução sexual, a corrupção mo-ral, a ociosidade, a ignorância e o fanatismo religioso são comuns a todos os escritores da época. Quanto ao pagamento do quinto do ouro e prata parece reparo de Froger, que anotou o mesmo. Mais grave é a observação de Sánchez Alonso de que o autor espanhol ter-se-ia influenciado pela campanha de difamação que contra a ação colonizadora de Espanha se iniciara antes e mais se exacerbara no século XVIII (o livro é de 1722). Por tudo isso enquanto não se fizerem pesquisas em Espanha e Holanda, a melhor opinião continua sendo a de Alfredo de Carvalho, segundo o qual "a existência dêste Globe Trotter do século XVII é, ainda, um problema a elucidar".

François Froger (1876-?) tinha 19 anos quando, como engenheiro voluntário, embarcou na esquadra de M. de Gennes, que ia fazer uma expedição ao Grande Oceano. A esquadra, composta de seis navios, partiu de Rochelle em 1695 e depois de pecorrer a costa africana chegou ao Rio a 20 de novembro, donde partiu a 5 de janeiro em direção ao Sul. A 11 de fevereiro entrou no estreito de Magalhães, donde se viu forçado a retornar ao Atlântico a 11 de abril. Em 16 de maio de 1696 navegava De Gennes em águas do Cabo Frio, onde se demorou, sendo a 20 de julho recebido na Bahia. A 21 de abril de 1679 chegava de volta a Rochelle.

François Froger conta que se exercitara no desênho, lera relações de viagens, familiarizara-se com a história de diferentes nações, e tinha sempre sua atenção voltada para o comércio, os interêsses particulares de cada colônia, as fôrças, a situação e vantagens de cada pôrto, os costumes, a religião, flora e fau-

\footnotetext{
(21). - Rubens Borba de Moraes, "Viagens"; in Manual Bibliográfico de Estudos Brasileiros, Rio de Janeiro, 1949, n.0 1772, p. 601.

(22). - História de la Historiografíab ob. ci.t, III, 54.
} 
na e procurava ser simples e exato. E' na Relation d'un voyage fait en 1695-96 \& 97 aux côtes d'Afrique, dedroit de Magellan, Brésil, Cayenne \& isles Antilles, par un escadre de vaisseaux du Roy, commandée par M. de Gennes (23), que Froger conta sua impressão de um mês e pouco no Rio e de menos de um mês na Bahia (24). Impressionou-se pela beleza natural do Rio, cujo pôrto era "une des plus seures \& des plus agreables de l'Amerique" mas foi acre e amargo com a gente, na sua maior parte composta de judeus $(3 / 4)$, traficantes de escravos, preguiçosa, licenciosa, amolecida e grave. Os religiosos são ignorantes e impuros, e entretêm mulheres públicas, sem temer a censura. O território é fértil em pastagens, mandioca, legumes e frutas, mas a riqueza principal é o açúcar. São Paulo, acrescenta êle, tem uma história bem particular: os paulistas atravessam todo o Brasil, viajam pelos rios, em grupos de 40 a 50 , e voltam 4 ou 5 meses depois com mais de 300 escravos índios, que conduzem como tropas de bois, e empregam no cultivo da terra ou na procura do ouro, "qu'ils trouvent en si grande quantité, que le Roy de Portugal, à qui ils envoyent scigneusemente le cinquième, en tire tous les ans plus de huit a neuf cens Marcs". A esquadra teve grandes dificuldades para desembarcar, em conformidade com os tratados, e o governador do Rio, Sebastião de Castro Caldas (1695-1697), deu provas de fraqueza contadas pelo próprio viajante (25) .

Foram essas dificuldades que fizeram a esquadra evitar 0 Rio, quando de volta do Estreito de Magalhães. Mas em Salvador, na Bahia, sucederam também alguns embaraços. Froger pinta os baianos muito parecidos com os cariocas nos traços essenciais: origem judaica, ardentes e sensuais, preguiçosos, muito religiosos. E se difere no louvor ao zêlo apostólico de alguns religiosos é porque êstes eram capuchos franceses, de que Martim e Bernardo de Nantes foram os paradigmas. Como no Rio, vê na Bahia o destrato dos negros escravos e censura a escravidão que corrompe a sociedade. A esquadra sesuiu para Caiena na Guiana Francesa, e agora as impressões de Froger deixam de ser desinteressadas, para servir às reivin-

\footnotetext{
(23). - Paris, 1698; 2a. ed. muito enriquecida de gravuras, Paris, 1699; trad. inglesa, Londres 1698; 4a. ed. Amsterdam, 1699. Há outras ediçốes de 1702 e 1715

(24) . - Afonso de E. Taunay resume os trechos capitais da relação no estudo "Froger", In Rio de Janeiro de Antanha, Brasiliana, vol. 222. São Paulo, 1942, 13-29.

(25). - A correspondência de Sebastião de Castro Caldas existente no Arquivo Nacional contém curiosas notícias sôbre êsse episódio. Vide Publicações do Arqứro Nacional, vol. XI, 1911. Vide sôbre o conflito para o desembarque F. A. de Varnhagen, História Geral do Brasil, 3a. ed. São Paulo, III, 303.
} 
dicações francesas no Amazonas, que pretendiam identificar, nesta altura, o Oiapoque com o próprio Amazonas (26).

William Dampier (1652-1715), corsário e navegador, foi um inglês inteiriço na época dos bucaneiros. Empreendeu viagens de pirataria e serviu ao almirantado inglês em navegações de descobrimento e exploração. Dotado do gênio da observação e escrevendo com fluência e agrado, o relato de suas viagens é surpreendentemente acurado e digno de fé. Hábil marinheiro, agudo observador, escritor agradável, Dampier foi a Newfoundland (Terra Nova), a Bantam (Java), trabalhou em Jamaica, comerciou em âmbar em Sumatra, fêz uma viagem ao redor do mundo de 1681 a 1691 e no "Roebuck", 1699, prestava serviços de exploração geográfica na Austrália para o Almirantado inglês. Comandou ainda o "St. George" em 1702-1706-1707, e ravegou como pilôto, com Woodes Rogens em 1708-1711. Dampier faleceu em Londres em março de 1715 (27).

Foi comandando o "Roebuck", navio eqüipado com 12 carhōes, com 50 homens e rapazes a bordo, e abastecido para 20 meses de cruzeiro, que W. Dampier conheceu e descreve o Brasil. A viagem era oficial e o navio de S. Majestade. Dampier saiu de Downs a 14 de janeiro e às 10 horas de 25 de março de 1699 entrava na Bahia, a mais considerável de tôdas as cidades do Brasil, seja pela beleza de suas construções, seja pelo seu comércio e rendas. Descreve-a melhor que qualquer outro viajante da época, notando características muito curiosas, já antes registadas pelos holandeses: a pobreza do mobiliário das casas e a falta de quadros. Era Salvador cidade de grande comércio, tendo Dampier encontrado mais de 30 navios que traficavam com a Europa, afora os barcos que negociavam com a Africa e os que faziam o transporte para outras praças brasileiras Eram poucos os mercadores e barcos estrangeiros, pois tudo devia ser embarcado em navios portuguêses: havia 10 ou 12 anos que não vinha barco inglês ao pôrto. Descreve o açúcar e seu refinamento, o comércio da Bahia, a pesca da baleia, os costumes, e o trabalho servil. Os negros constituiam o grosso dos habitantes e os próprios profissionais executavam os servi-

(26). - Froger desenhou de acôrdo com as instruçōes de De Ferrolles (Pierre Elenor de la Ville, senhor de), chefe militar da Guiana e instrumento da pretensão francesa, uma "Carte du Gouvernement de Cayenne ou France Aequinoctiale". Rio Branco retificou os erros de Froger na Carta e no Texto. Cf. Frontières entre le Brésil et la Guyane Française. Seconde Mermoire Presentée par les E. U. du Brésil, etc. Berna, 1899, t. 2, 191-194; na reedição, Rio de Janeiro, 1945 , vols. I e II, várias páginas.

(27). - Vide verbete assinado por Charles Raymond Beazley na Encyclopedia Britanica e E. Clark Russel, William Dampier, Londres, 1889 . 
ços à custa de escravos. Relata as riquezas naturais, a flora e a fauna e depois de uma ligeiríssima referência aos dois outros portos consideráveis, Pernambuco e Rio de Janeiro, trata do famoso São Paulo, cujo renome de riqueza aurífera e de independência de caráter inflamava a imaginação de todos os brasileiros e dos estrangeiros que aqui aportavam, pois logo ouviam falar dos paulistas, "uma espécie de bandidos" ricos e independentes. Dampier esteve um mês na Bahia e só partiu depois de aguardar os ventos favoráveis que facilitassem a travessia para o Cabo da Boa Esperança, e o mais cêdo possíve!, temeroso que andava do tribunal do Santo Ofício.

As Viagens de Dampier foram editadas várias vêzes independentemente e em coleções e traduzidas para o francês, mas nunca para o português (28).

JOSE' HONÓRIO RODRIGUES

Diretor do Arquivo Nacional (Rio de Janeiro).

(28). - A New Voyage Round the World. Voyage land Descriptions. A Voyage to New Holland, 1697-1709; A Collection of Voynges, Londres, 1729, 2 vols.; Voyages aux Terres Australes, à la Nouvelle Hollande, Ruão, 1715 e A New Voyago round the world, Londres, 1927 (ed. de 975 exs. feita pelo presidente da Hakluyt Society e considerada a melhor; várias ediçōes e traduçōes registadas in The Bristish Museum Catalakuse of Printed Books, Anp Arbor, 1946. 